HPB Surgery 1990, Vol.2, p.149

Reprints available directly from the publisher

Photocopying permitted by license only
(C) 1990 Harwood Academic Publishers GmbH Printed in the United Kingdom

\title{
HPB NEWS
}

\section{HPB IN SOVIET UNION}

Ministry of Health of the USSR, All-Union Scientific Society of Surgeons, decided at a meeting on November 28, 1989, to set up a hepato-pancreato-biliary surgery section of All-Union Society of Surgeons. Professor Eduard Galperin was appointed chairman of the section. It was decided that the section should participate in the activities of the World HPB Surgery Association.

After this the HPB World Association has received 25 new members from Soviet Union. The number of members in the Soviet Union is at present 27.

The national delegate for Soviet Union is

Professor Eduard I. Galperin

Department of Surgery

1st Moscow Medical Institute

Hospital 7

Kolomensky Proezd 4

MOSCOW

Soviet Union

\section{HPB WORLD ASSOCIATION}

Some countries have appointed new national delegates to the HPB World Association.

Country:

Denmark

New Zealand
Delegate:

Susanne Lone Jensen, M.D.

Surgical Gastroenterological

Department L

Århus Kommunehospital

DK-8000 ÅRHUS C

Richard Stubbs, M.D.

Department of Surgery

Wellington School of Medicine

Wellington Hospital

P.O. Box 7343

Wellington South 


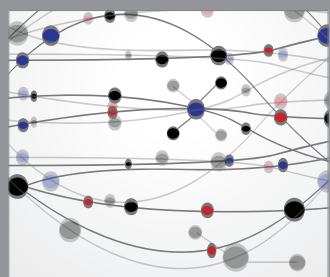

The Scientific World Journal
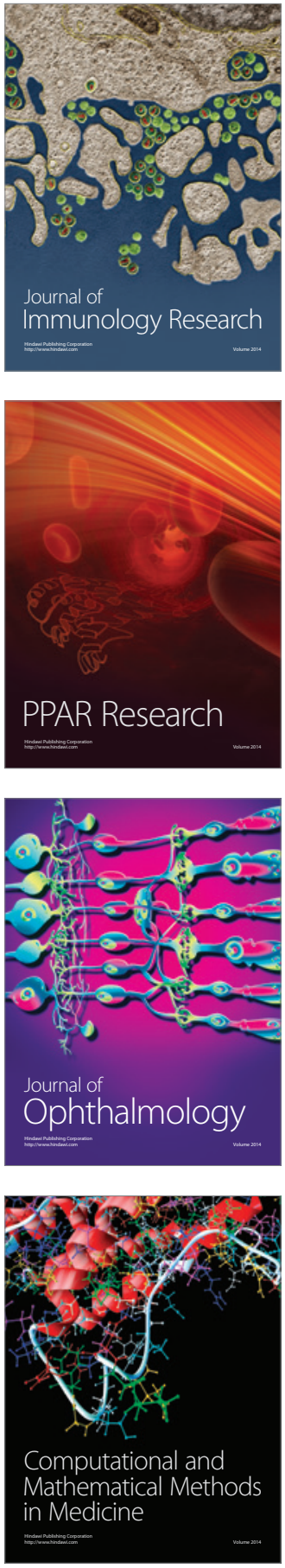

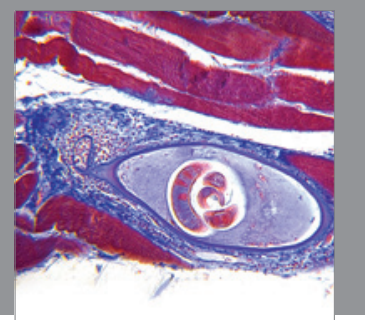

Gastroenterology

Research and Practice
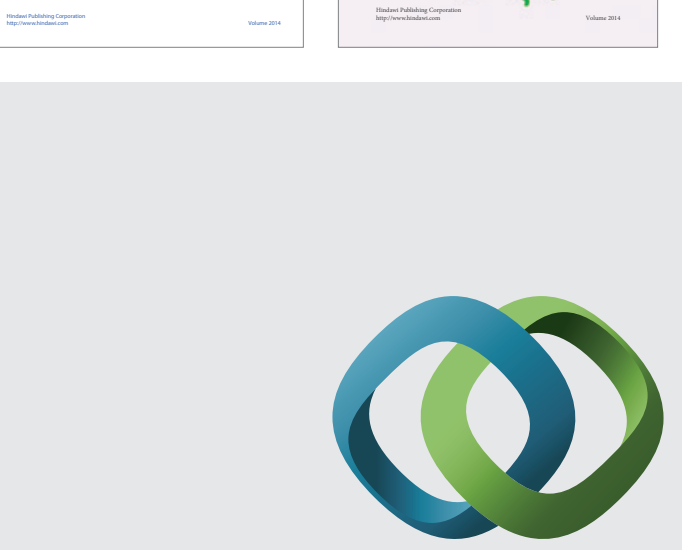

\section{Hindawi}

Submit your manuscripts at

http://www.hindawi.com
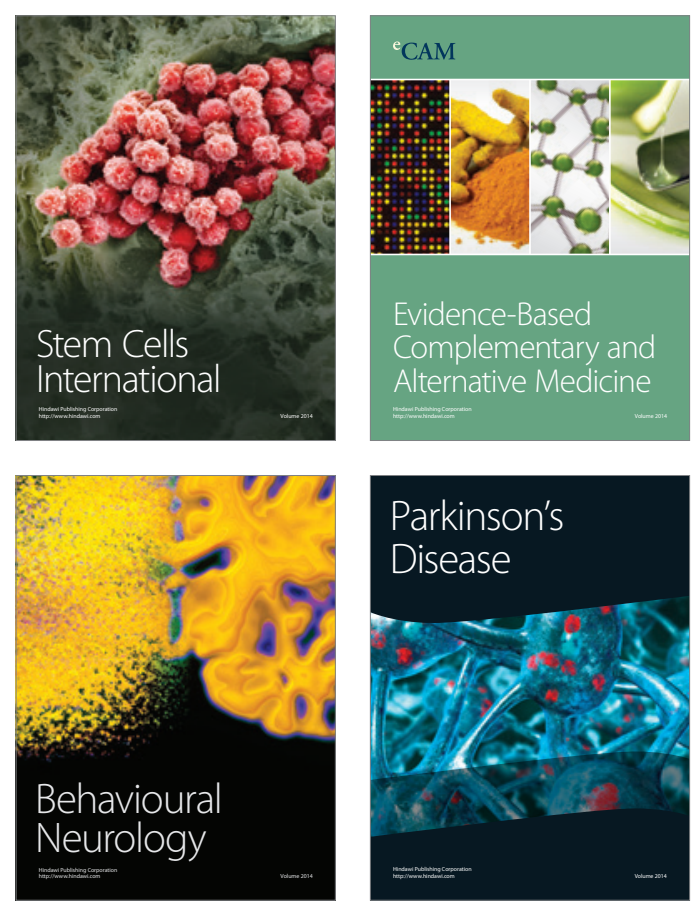

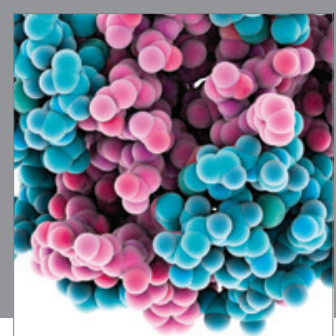

Journal of
Diabetes Research

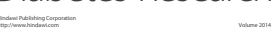

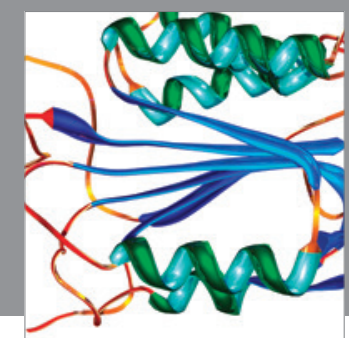

Disease Markers
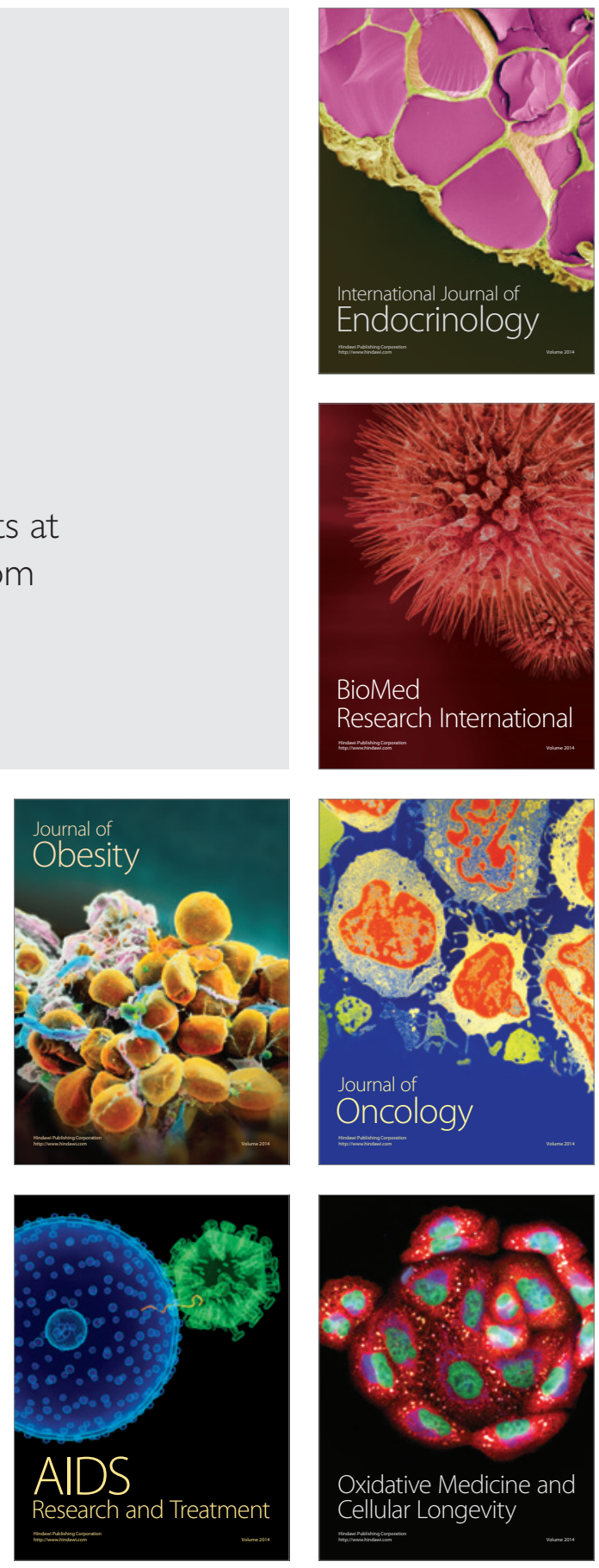